\title{
PEMETAAN SMK DI JAWA BARAT, BANGKA BELITUNG DAN KALIMANTAN TENGAH
}

\author{
Yadi Mulyadi $\quad$ Mukhidin $^{1}$ Agus Setiawan, Aam Hamdani dan Purnawan ${ }^{2}$
}

Abstrak: Sejak tahun 2005 Direktorat PSMK telah mencanangkan program nasional pengembangan SMK secara besar-besaran dengan skenario penambahan jumlah siswa SMK dan pengurang jumlah siswa SMA atau dikenal dengan skema 70:30. Pertimbangan fundamental nya adalah mengurangi tingkat pengangguran di level lulusan SMA akibat tidak dapat meneruskan studi ke jenjang lebih tinggi. Sedangkan memperluas pendidikan SMK diharapkan daya serap lapangan kerja di industri semakin besar.

Implikasi dari program nasional di atas adalah terjadinya 'booming' SMK-SMK baru dari kota sampai ke berbagai pelosok daerah. Beberapa SMK baik negeri maupun swasta bermunculan secara cepat, bahkan di beberapa daerah ada gedung SD, SMP atau SMK yang dipakai untuk membuat SMK. Kondisi ini tentunya sangat mengkhawatirkan, di satu sisi sejalan dengan program nasional namun di sisi lain peningkatan kuantitas tersebut tidak berkorelasi linear dengan kualitas. Belum lagi kesesuaian program kompetensi SMK tersebut apakah sudah melewati studi kajian yang mendalam sehingga akan memberikan dampak terhadap daya serap industri.

Oleh karena itulah secara berkala perlu dilakukan pemetaan secara komprehensif terhadap seluruh SMK yang ada mulai dari ketersediaan guru, program keahlian, infra struktur, perkembangan siswa, penambahan jumlah guru, daya minat masyarakat, termasuk program-program yang dilaksanakan di SMK.

Metode yang digunakan dalam melakukan penelitian berupa descriptive methode, yaitu menggambarkan kondisi SMK yang ada di masing-masing daerah studi. Data dikumpulkan dengan metode sensus dan dokumentasi. Penelitian ini telah menghasilkan data untuk ketiga daerah studi Jabar, Babel, dan Kalteng secara berurutan sebagai berikut : (1) Jumlah SMK: 1043, 43, 67 ;(2) Jumlah Rombel: 9454, 418, 446; (3) Jumlah PSB : 134988, 5782; 5764; (4) Jumlah Siswa : 327757, 14482, 14010; (5) Jumlah lulusan : 81916, 2517, 2586.

\begin{abstract}
Since 2005 the Directorate of Vocational High School Development (Direktorat PSMK) has launched a national program of vocational high school (SMK) development on a large scale with the scenario of increasing the quantity vocational high school students and reducing the number of senior high school students (SMA) or known by the scheme of 70:30. Its fundamental consideration is to reduce the unemployment rate of SMA graduates can who not continue to studies to their further higher level of education. While the development of vocational education is expected to expand the employment absorption in the greater world of industry. The implications to the above national program significance of the increasing numbers of new SMK spreading from both in urban and rural . Some of both public and private vocational schools has emerged quickly, even in some areas there are primary school, junior or vocational school used to make the CMS. This condition is certainly worrying, on the one side it is line with the national program but on the other side the increase in quantity does not linearly correlate with the quality. More over the relevence of the SMK competence program has not been thoroughly examined an in depth study that can give an impact on the employment absorption in the world of indutry. Aperiodically comprehensive mapping of the all existing vocational the schools need tobe done ranging especially from the availability of the teachers the program expertise as well as the and the infrastructure as well as development of the students, including the increasing the number of teachers, the interest of the community as well as programs being carried out in SMK. The method used in conducting the research is a descriptive method, this method describes the condition of the existing vocational schools in each subject study area. Data is collected through using the census method and documentation methods. This research has produced data for all three subject study areas in West Java, Bangka Belitung and Central Kalimantan and has sequentially resulted as follows: (1) Number of SMK: 1043, 43, 67, (2) Number learning group: 9454, 418, 446, (3) Number of learning resource centre: 134 988, 5782, 5764, (4) Number of Students: 327,757, 14,482, 14,010, (5) Number of graduates: 81 916, 2517, 2586.
\end{abstract}

Kata Kunci : Pemetaan SMK, Skenario 70:30, Perkembangan Siswa SMK, Kebutuhan Guru

547

${ }^{1}$ Drs. Yadi Mulyadi, MT, Prof. Dr. Mukhidin, M.Pd. adalah dosen di Jurusan Pendidikan Teknik Elektro FPTK UPI

${ }^{2}$ Dr. Eng Agus Setiawan,M.Si., Drs. Aam Hamdani, MT dan Purnawan, S.Pd., MT adalah dosen di Jurusan Pendidikan Tknik Mesin FPTK UPI. 


\section{PENDAHULUAN Rasional}

Dalam mengantisipasi meningkatnya angka pengangguran usia produktif, pemerintah mendorong untuk dikembangkannya jumlah SMK di seluruh kabupaten/kota hingga akhirnya akan dicapai perbandingan antara SMK dengan SMU menjadi 70 : 30. Hal ini berdasarkan anggapan bahwa lulusan SMK lebih mudah masuk ke pasar kerja daripada lulusan SMA karena umumnya mata pelajaran di SMK sudah disertai dengan praktik keterampilan sehingga diharapkan lulusan SMK dapat bekerja pada orang lain atau membuka lapangan kerja sendiri.

Namun
pengembangan direncanakan secara komprehensif sehingga pengembangan tersebut tidak hanya menyangkut kuantitas tetapi juga harus menyangkut kualitas, produktifitas, dan relevansi agar tujuan sebenarnya dari pengembangan tersebut dapat diwujudkan. Upaya pengembangan SMK hingga mencapai 70 \% dibandingkan dengan SMU, tentunya akan membutuhkan sumber daya manusia (SDM) yang kompeten dibidangnya, sehingga pengelolaan SMK akan mencapai efisiensi dan efektivitas yang tinggi. Dalam tataran mikro, diantara sumber daya manusia yang sangat dibutuhkan pada kegiatan pembelajaran di SMK adalah guru.

Secara sistemik, output berkaitan erat dengan proses, dan proses terkait dengan input, sehingga kualitas proses akan berimplikasi langsung terhadap kualitas hasil. Berdasarkan hal tersebut, upaya peningkatan mutu lulusan SMK berkaitan erat dengan peningkatan mutu proses pembelajaran, dengan guru merupakan salah satu instrumental input dominannya. Dengan demikian peningkatan guru baik secara kualitas dan kuantitas merupakan keharusan untuk memecahkan masalah kualitas pendidikan yang terjadi saat ini. Upaya peningkatan guru tersebut sejalan dengan permasalahan pada guru itu sendiri. Dikaitkan dengan data tahun 2004 - 2005 permasalahan guru khususnya di SMK diantaranya : (1) jumlah pendidik dan tenaga kependidikan belum memadai (masih kekurangan 11.502 orang), (2) Distribusi guru yang tidak merata dan menumpuk di daerah-daerah perkotaan, (3) Kualifikasi dan kompetensi yang belum memenuhi standar nasional pendidikan $(35,51 \%$ berijazah dibawah D4/S1), (4) Masih banyaknya guru yang mengajar tidak sesuai dengan bidang keahliannya (mismatch) (43,3\% diindikasikan tidak layak mengajar), dan (5) Terbatasnya kemampuan pemerintah dalam pemenuhan kebutuhan guru (PNS).

Guru sebagai input dominan yang berfungsi sebagai agen perubahan pembelajaran yang profesional, sesuai dengan Undang-Undang Guru dan Dosen dan juga Standar Nasional Pendidikan setidaknya harus memiliki tiga pilar yaitu (1) kualifikasi, (2) kompetensi agen pembelajaran, sehat jasmani dan rohani, memiliki kemampuan untuk mewujudkan tujuan pendidikan nasional serta memiliki (3) sertifikat. Dengan demikian guru harus memiliki kualifikasi yang dipersyaratkan, kompetensi yang terstandar, dan mampu mendukung dan menyelenggarakan pendidikan secara profesional sehingga akan menghasilkan mutu pendidikan yang baik.

Pemetaan guru telah banyak dilakukan oleh berbagai pihak, namun belum menggambarkan kebutuhan spesifik dalam pengembangan pendidikan berbasis keunggulan lokal. Input tenaga pendidik yang dibutuhkan dalam pengembangan pendidikan berbasis keunggulan lokal diantaranya meliputi relevansi antara kualifikasi, kompetensi, dan sertifikasi dengan potensi yang dimiliki oleh daerah dimana tenaga pendidik itu melaksanakan tugas. Guna menghasilkan data tenaga pendidik yang valid dan up to date sesuai dengan kebutuhan daerah setempat, dan dalam program pengembangan SMK secara nasional maka diperlukan studi pemetaan yang lebih spesifik yang akan dilakukan melalui kegiatan ini. 


\section{TINJAUAN PUSTAKA}

Sekolah Menengah Kejuruan (SMK) adalah salah satu bentuk satuan pendidikan formal yang menyelenggarakan pendidikan kejuruan pada jenjang pendidikan menengah sebagai lanjutan dari SMP, MTs, atau bentuk lain yang sederajat. Sebagai bagian dari sistem Pendidikan Nasional, SMK merupakan pendidikan lebih mengutamakan pengembangan kemampuan peserta didik untuk dapat bekerja dalam bidang tertentu, kemampuan beradaptasi di lingkungan kerja, melihat peluang kerja dan mengembangkan diri di kemudian hari.

Sejalan dengan perkembangan pendidikan teknologi dan kejuruan pada saat ini, pendidikan dan latihan menjadi salah satu program pokok dalam mencapai standar profesi khususnya peningkatan keterampilan. Hal ini sesuai dengan dalildalil pendidikan kejuruan yang diungkapkan Prosser dikutip oleh Suharsimi (1988), sebagai berikut :

1. Latihan kejuruan yang efektif hanya dapat diberikan jika tugas-tugas yang diberikan di dalam latihan memiliki kesamaan operasional dengan peralatan yang sama dan dengan mesin-mesin yang sama dengan yang akan dipergunakan di dalam kerjanya kelak.

2. Pendidikan kejuruan akan efektif jika sejak latihan sudah dibiasakan dengan perilaku yang akan ditujukan dalam pekerjaannya kelak.

3. Pendidikan kejuruan akan efektif apabila pelatihnya cukup berpengalaman dan mengetrapkan kemampuan dan keterampilannya di dalam mengajar.

4. Untuk setiap pekerjaan selalu ada minimum kemampuan yang harus dimiliki oleh individu agar bisa menjabat pekerjaan itu. Jika pendidikan tidak diarahkan pada pencapaian persyaratan minimal tersebut maka tentu individu akan merasakan kerugian, demikian juga masyarakat.
5. Pendidikan kejuruan harus mengenal kondisi kerja dan harus memenuhi harapan "pasar".

Dalil-dalil tersebut memberi gambaran bahwa pendidikan kejuruan yang efektif adalah pendidikan kejuruan yang dalam program-program pendidikan maupun latihannya berorientasi pengalaman, dunia kerja, dan peserta didik.

Thompson (1973), menyatakan bahwa pendidikan kejuruan adalah suatu pendidikan yang memberikan pengalaman, stimulus visual, pengetahuan afektif, informasi kognitif, atau keterampilan psikomotor; mempertinggi penyelidikan pengembangan vokasional; serta menciptakan dan memelihara sendiri dalam dunia kerja. Pendapat Thompson ini memiliki cakupan luas, yang menempatkan subyek didik dalam suatu orientasi ke masa depan. Artinya, anak didik dituntut untuk mengadakan penyelidikan, menciptakan dan memelihara dalam rangka pengembangan keahlian tersebut di dunia kerja. Jadi anak didik tidak hanya dibekali kemampuan teknis bekerja saja.

Wenrich dan Wenrich (1974), mendefinisikan pendidikan kejuruan sebagai suatu pendidikan spesialisasi, yang diorganisir untuk mempersiapkan peserta didik memasuki jabatan khusus. Jadi dalam pendidikan kejuruan, seharusnya peserta didik telah dimantapkan dan dikembangkan secara terarah, guna memiliki kemampuan dan keahlian yang siap pakai dan siap kerja.

Selain itu, Sukamto (1988), mengungkapkan bahwa pendidikan kejuruan merupakan upaya menyediakan stimulus berupa pengalaman belajar dan interaksi dengan dunia di luar diri peserta didik untuk membantu mereka mengembangkan diri potensinya. Hal ini menunjukkan bahwa setiap peserta didik mempunyai potensi dalam dirinya, yang dapat dikembangkan salah satunya melalui interaksi dengan dunia luar baik itu rangsangan-rangsangan teknologi maupun sosial-budaya.

Lebih lanjut mengenai tujuan pendidikan kejuruan, Thorogood (1982), menyatakan bahwa di sebagian negara besar, 
negara anggota Organization for Economic Corporation and Development (OECD), pendidikan kejuruan bertujuan yakni :

a. memberi bekal keterampilan individu dan keterampilan yang laku di masyarakat, sehingga peserta didik secara ekonomis dapat menopang kehidupannya,

b. membantu peserta didik memperoleh atau mempertahankan pekerjaan dengan jalan memberi bekal keterampilan yang berkaitan dengan pekerjaan yang diinginkan,

c. mendorong produktivitas ekonomi secara regional maupun nasional,

d. mendorong terjadinya tenaga terlatih untuk menopang perkembangan ekonomi dan industri, dan

e. meningkatkan kualitas masyarakat.

Evans (1971), merinci tujuan pendidikan kejuruan menjadi tiga hal, yaitu (a) memenuhi kebutuhan masyarakat akan tenaga kerja, (b) meningkatkan pilihan profesi untuk setiap peserta didik, dan (c) memberikan motivasi untuk mempelajari yang lain.

Tujuan pendidikan kejuruan yang telah diungkapkan tersebut dapat disimpulkan bahwa pendidikan kejuruan mengemban misi khusus, yaitu memberi bekal pengetahuan dan keterampilan kepada peserta didik untuk memasuki lapangan kerja, dan sekaligus menghasilkan tenaga kerja yang terampil.

Untuk mencapai tujuan pendidikan kejuruan sebagaimana tersebut di atas, diperlukan suatu sistem pembelajaran yang memiliki kualitas, efektifitas, dan relevansi yang tinggi, sehingga akan dapat menghasilkan lulusan yang profesional dan berkualitas yang mampu bersaing dalam mengisi kebutuhan pembangunan. Keberhasilan proses pembelajaran tergantung pada komponen-komponen dalam sistem pembelajaran tersebut, dimana komponen utamanya adalah guru sebagai agennya.

Guru sebagai SDM yang ada di sekolah khususnya SMK mempunyai peranan yang sangat menentukan dan merupakan kunci keberhasilan dalam mencapai tujuan pendidikan, karena guru adalah pengelola pembelajaran bagi para siswa. Jika guru kurang memiliki kompetensi yang cukup memadai, maka hasil belajar yang diperoleh kurang baik. Agar pelaksanaan pembelajaran berjalan dengan efektif dan efisien sesuai dengan tujuan yang akan dicapai, diperlukan guru yang profesional dan berkualitas sesuai dengan kebutuhan tiap-tiap SMK baik jumlah, kualifikasi maupun spesialisasinya. Hal ini sejalan dengan Undang-undang Nomor 14 tahun 2005 tentang guru dan dosen yang menyatakan bahwa guru adalah pendidik profesional dengan tugas utama mendidik, mengajar, membimbing, mengarahkan, melatih, dan mengevaluasi. Dalam pasal 8 disebutkan bahwa guru harus memiliki kualifikasi akademik, kompetensi, sertifikat pendidik, sehat jasmani dan rohani, serta memiliki kemampuan untuk mewujudkan tujuan nasional. Kompetensi guru yang dimaksud meliputi komptensi pedagogik, kepribadian, sosial, dan profesional.

Pelaksanaan pembelajaran di SMK lebih banyak menekankan pada pembelajaran praktik, sehingga keberadaan fasilitas yang berupa sarana dan prasarana praktik sangat diperlukan. Upaya yang telah dilakukan pemerintah berupa penataan kembali kebijakan pendidikan kejuruan khususnya SMK dengan disertai pembangunan sarana dan prasarana praktik atau laboratorium. Sarana yang berupa gedung dan prasarana yang berupa alat-alat praktik merupakan identitas dari suatu Sekolah Menegah Kejuruan. Oleh karena itu, maka kompetensi guru SMK terutama yang guru mata pelajaran produktif dalam memanfaatkan sarana dan prasarana praktik sangat diperlukan. Kemampuan guru dalam memanfaatkan sarana dan prasarana praktik yang baik akan memperlancar kegiatan pembelajaran praktik, sehingga kompetensi lulusan SMK akan dapat ditingkatkan.

Pasal 35 ayat (1) Undang-undang Nomor 14 Tahun 2005 tentang Guru dan Dosen menyebutkan bahwa kewajiban guru mencakup kegiatan pokok dan tugas 
tambahan. Kegiatan pokok seorang guru adalah merencanakan pembelajaran, melaksanakan pembelajaran, menilai hasil pembelajaran, membimbing dan melatih peserta didik. Sedangkan tugas tambahan guru meliputi tugas tambahan struktural dan tugas tambahan khusus yang hanya berlaku pada jenis sekolah tertentu, untuk menangani masalah khusus yang belum diatur dalam peraturan yang mengatur organisasi sekolah. Sedangkan beban kerja seoarang guru dituangkan dalam pasal 35 ayat (2) yang menyatakan bahwa beban kerja guru sekurang-kurangnya 24 jam tatap muka dan sebanyak-banyaknya 40 jam tatap muka dalam 1 (satu) minggu.

Dalam melaksanakan tugas pokok yang terkait langsung dengan proses pembelajaran, guru hanya melaksanakan tugas mengampu 1 (satu) jenis mata pelajaran saja, sesuai dengan kewenangan yang tercantum dalam sertifikat pendidiknya. Disamping itu, guru sebagai bagian dari manajemen sekolah, akan terlibat langsung dalam kegiatan manajerial tahunan sekolah, yang terdiri dari siklus kegiatan perencanaan, pelaksanaan dan evaluasi. Rincian kegiatan tersebut antara lain penerimaan siswa baru, penyusunan kurikulum dan perangkat lainnya, pelaksanaan pembelajaran termasuk tes/ulangan, Ujian Nasional (UN), ujian sekolah, dan kegiatan lain. Tugas tiap guru dalam siklus tahunan tersebut secara spesifik ditentukan oleh manajemen sekolah tempat guru bekerja.

Sebagai tenaga profesional, guru baik PNS maupun bukan PNS dalam melaksanakan tugasnya berkewajiban memenuhi jam kerja yang setara dengan beban kerja pegawai lainnya yaitu 37,5 (tiga puluh tujuh koma lima) jam kerja (@60 menit) per minggu. Dalam melaksanakan tugas, guru mengacu pada jadwal tahunan atau kalender akademik dan jadwal pelajaran. Kegiatan tatap muka dalam satu tahun dilakukan kurang lebih 38 minggu atau 19 minggu per semester. Kegiatan tatap muka guru dialokasikan dalam jadwal pelajaran yang disusun secara mingguan. Khusus Sekolah Menengah
Kejuruan (SMK) ada kalanya jadwal pelajaran tidak disusun secara mingguan, tapi mengunakan sistim blok atau perpaduan antara sistim mingguan dan blok. Pada kondisi ini, maka jadwal pelajaran disusun berbasis semester, tahunan, atau bahkan per tiga tahunan. Diluar kegiatan tatap muka, guru akan terlibat dalam aktifitas persiapan tahunan/semester, ujian sekolah maupun Ujian Nasional (UN), dan kegiatan lain akhir tahun/semester.

Studi pendahuluan telah berhasil mengidetifikasi permasalahan guru SMK secara nasional berdasarkan data tahun 2004 - 2005 diantaranya : (1) jumlah pendidik dan tenaga kependidikan belum memadai (masih kekurangan 11.502 orang), (2) Distribusi guru yang tidak merata dan menumpuk di daerah-daerah perkotaan, (3) Kualifikasi dan kompetensi yang belum memenuhi standar nasional pendidikan $(35,51 \%$ berijazah dibawah D4/S1), (4) Masih banyaknya guru yang mengajar tidak sesuai dengan bidang keahliannya (mismatch) (43,3\% diindikasikan tidak layak mengajar), dan (5) Terbatasnya kemampuan pemerintah dalam pemenuhan kebutuhan guru (PNS).

Metode yang digunakan dalam penelitian ini adalah descriptive methode, yaitu menggambarkan kondisi SMK yang ada di masing-masing Kabupaten/kota pada daerah studi terutama yang berkaitan dengan kondisi guru yang ada dan pengembangan program keahlian. Pendekatan yang digunakan dalam studi ini terdiri dari pendekatan kuantitatif dan kualitatif. Berdasarkan pendekatan tersebut, data dikumpulkan dengan metode sensus dan dokumentasi.

Langkah kegiatan yang dilakukan dalam studi ini adalah sebagai berikut: pertama, Studi pendahuluan dilakukan untuk mengumpulkan data profil guru SMK dan data program keahlian yang dilaksanakan oleh semua SMK di Indonesia. Data tersebut diperoleh dari Direktorat Pembinaan SMK, Ditjen Mandikdasmen. Sedangkan metode dokumentasi dilakukan dengan pengumpulan data sekunder yang ada di dinas pendidikan kabupaten/kota daerah studi. Kedua, 
menyususun desain penelitian, Ketiga, menyususun kisi-kisi dan instrumen penelitian serta melakukan ujicoba instrumen. Keempat, melakukan pengumpulan data. Data sekunder diperoleh dengan pengumpulan data yang dalam studi ini dilakukan dengan pendekatan sensus di 1286 SMK baik SMK Negeri maupun SMK Swasta. Namun dengan mempertimbangkan dana yang tersedia dan lain-lain, maka pengumpulan data dilakukan dengan pengambilan data secara sampling dengan tetap mempertimbangkan keakuratan data. Kelima, Pengolahan data dan analisis terhadap data yang telah dikumpulkan.
PEMBAHASAN HASIL PENELITIAN

Data-data yang didapatkan dari kegiatan penelitian berdasarkan data dari Dinas Pendidikan Propinsi daerah studi sebagai data primer, data dari Dirjen Pembinaan Sekolah Menengah Kejuruan (PSMK) dan data dari sekolah sampel sebagai data sekunder . Data secara lengkap terdapat dalam lampiran laporan penelitian ini. Deskripsi data yang diperoleh melalui kegiatan ini ditunjukkan pada tabel-tabel sebagai berikut :

\section{Data Jumlah SMK}

Tabel 1. Data jumlah SMK daerah studi

\begin{tabular}{|c|c|c|}
\hline No. & KBUPATEN / KOTA & JMLSMK \\
\hline 1 & KABUPATENBOGOR & 87 \\
\hline 2 & KABUPATENSUKABUM & 34 \\
\hline 3 & KABUPATENOANJUR & 43 \\
\hline 4 & KABUPATENBANDUNG & 72 \\
\hline 5 & KABUPATENGARUT & 45 \\
\hline 6 & KABUPATENTASIKMALAYA & 31 \\
\hline 7 & KABUPATENOAMS & 27 \\
\hline 8 & KABUPATENKUNNGAN & 33 \\
\hline 9 & KABUPATENARBON & 47 \\
\hline 10 & KABUPATENMAJALENGKA & 30 \\
\hline 11 & KABUPATENSUMEDANG & 31 \\
\hline 12 & KABUPATENINDRAMAYU & 35 \\
\hline 13 & KABUPATENSUBANG & 34 \\
\hline 14 & KABUPATENPURWAKARTA & 21 \\
\hline 15 & KABUPATENKARAWANG & 39 \\
\hline 16 & KABUPATENBEKASI & 64 \\
\hline 17 & KOTA BOGOR & 60 \\
\hline 18 & KOTA SUKABUM & 17 \\
\hline 19 & KOTA BANDUNG & 70 \\
\hline 20 & KOTA GRBON & 18 \\
\hline 21 & KOTA BEKASI & 60 \\
\hline 22 & KOTA DEOK & 59 \\
\hline 23 & КОТА СМАН & 18 \\
\hline 24 & KOTA TASIKMALAYA & 28 \\
\hline 25 & KOTA BANJAR & 10 \\
\hline 26 & KABUPATENBANDUNG BARAT & 30 \\
\hline \multicolumn{2}{|r|}{ JUMLAH } & 1043 \\
\hline
\end{tabular}

\begin{tabular}{|c|l|c|}
\hline No. & \multicolumn{1}{|c|}{ Kota/ kabupaten } & JML SMK \\
\hline 1 & KOTA PANGKAL PINANG & 8 \\
\hline 2 & KABUPATENBANGKA & 8 \\
\hline 3 & KABUPATENBANGKA BARAT & 7 \\
\hline 4 & KABUPATENBANGKA TENGAH & 5 \\
\hline 5 & KABPATIENBANGKA SE_ATAN & 3 \\
\hline 6 & KABUPATENBEITUNG & 7 \\
\hline 7 & KABUPATENBEITUNG TIMUR & 5 \\
\hline \multicolumn{2}{r|}{ Jumlah } & 43 \\
\hline
\end{tabular}

\begin{tabular}{|c|c|c|}
\hline No. & KABUPATEN/ KOTA & JML SMK \\
\hline 1 & KABUPATENKOTAWARINGINBARAT & 6 \\
\hline 2 & KABUPATENKOTAWARINGINTIMR & 12 \\
\hline 3 & KABUPATENKAPUAS & 7 \\
\hline 4 & KABUPATENBARTOSEATAN & 1 \\
\hline 5 & KABUPATENBARTOUTARA & 5 \\
\hline 6 & KABUPATENKATINGAN & 6 \\
\hline 7 & KABUPATENSERUYAN & 4 \\
\hline 8 & KABUPATENSUKAMARA & 2 \\
\hline 9 & KABUPATENLAMANDAU & 2 \\
\hline 10 & KABUPATENGUNUNGMAS & 2 \\
\hline 11 & KABUPATENPULANG PISAU & 3 \\
\hline 12 & KABUPATENMRUNG RAYA & 1 \\
\hline 13 & KABUPATENBARTOTIMR & 3 \\
\hline 14 & KABUPATENPALANGARAYA & 13 \\
\hline & JUMAH & 67 \\
\hline
\end{tabular}


2. Data rombongan belajar, PSB, dan lulusan

Tabel 2. Data rombongan belajar, PSB, dan lulusan SMK di Babel

\begin{tabular}{|c|c|c|c|c|c|c|c|c|c|c|c|}
\hline \multirow{3}{*}{ No. } & \multirow{3}{*}{ KOTA / KABUPATEN } & \multirow{3}{*}{$\begin{array}{l}\bar{\Phi} \\
\text { है } \\
\text { Q }\end{array}$} & \multicolumn{6}{|c|}{ PSB } & \multirow{2}{*}{\multicolumn{3}{|c|}{ Lulusan }} \\
\hline & & & \multicolumn{3}{|c|}{ Pendaftar } & \multicolumn{3}{|c|}{ Diterima } & & & \\
\hline & & & L & $\mathrm{P}$ & $\mathrm{T}$ & L & $\mathrm{P}$ & $\mathrm{T}$ & L & $\mathrm{P}$ & $\mathrm{T}$ \\
\hline 1 & KOTA PANGKAL PINANG & 170 & 1272 & 1278 & 2518 & 881 & 859 & 1740 & 533 & 655 & 1188 \\
\hline 2 & KABUPATENBANGKA & 94 & 1041 & 926 & 1967 & 602 & 519 & 1121 & 276 & 308 & 584 \\
\hline 3 & KABUPATENBANGKA BARAT & 52 & 501 & 475 & 976 & 384 & 299 & 683 & 102 & 177 & 279 \\
\hline 4 & KABUPATENBANGKA TENGAH & 37 & 402 & 409 & 811 & 327 & 259 & 586 & 85 & 71 & 156 \\
\hline 5 & KABUPATENBANGKA SEATAN & 28 & 263 & 157 & 420 & 224 & 147 & 371 & 73 & 38 & 111 \\
\hline 6 & KABUPATENBELTUNG & 26 & 512 & 555 & 1067 & 485 & 465 & 950 & 23 & $\mathrm{O}$ & 23 \\
\hline 7 & KABUPATENBE TUNG TIMRR & 15 & 212 & 229 & 441 & 183 & 164 & 347 & 82 & 59 & 141 \\
\hline & Jumlah & 422 & 4203 & 4029 & 8200 & 3086 & 2712 & 5798 & 1174 & 1308 & 2482 \\
\hline
\end{tabular}

Tabel 3. Data rombongan belajar, PSB, dan lulusan SMK di Kalteng

\begin{tabular}{|c|c|c|c|c|c|c|c|c|c|c|c|}
\hline \multirow{3}{*}{ No. } & \multirow{3}{*}{ KABUPATEN/ KOTA } & \multirow{3}{*}{$\begin{array}{l}\bar{\nabla} \\
\text { है } \\
\text { ष्प }\end{array}$} & \multicolumn{6}{|c|}{ PSB } & \multirow{2}{*}{\multicolumn{3}{|c|}{ Lulusan }} \\
\hline & & & \multicolumn{3}{|c|}{ Pendaftar } & \multicolumn{3}{|c|}{ Diterima } & & & \\
\hline & & & L & $P$ & $T$ & L & $P$ & $T$ & L & $P$ & $T$ \\
\hline 1 & KABUPATEN KOTAWARINGINBARAT & 50 & 601 & 543 & 1144 & 397 & 319 & 716 & 215 & 214 & 429 \\
\hline 2 & KABUPATEN KOTAWARINGINTIMUR & 69 & 937 & 715 & 1652 & 605 & 378 & 983 & 248 & 179 & 427 \\
\hline 3 & KABUPATENKAPUAS & 42 & 265 & 192 & 457 & 263 & 189 & 452 & 136 & 112 & 248 \\
\hline 4 & KABUPATENBARTO SEATAN & 16 & 79 & 69 & 148 & 78 & 69 & 147 & 46 & 68 & 114 \\
\hline 5 & KABUPATENBARTOUTARA & 41 & 344 & 167 & 511 & 329 & 147 & 476 & 81 & 78 & 159 \\
\hline 6 & KABUPATENKATINGAN & 19 & 153 & 142 & 295 & 150 & 142 & 292 & 108 & 143 & 251 \\
\hline 7 & KABUPATENSERUYAN & 15 & 214 & 139 & 353 & 203 & 123 & 326 & 26 & 22 & 48 \\
\hline 8 & KABUPATENSUKAMARA & 9 & 109 & 97 & 206 & 109 & 97 & 206 & o & $\mathrm{O}$ & $\mathrm{O}$ \\
\hline 9 & KABUPATENLAMANDAU & 13 & 107 & 61 & 168 & 106 & 61 & 167 & 16 & 13 & 29 \\
\hline 10 & KABUPATENGUNUNGMAS & 9 & 72 & 57 & 129 & 72 & 57 & 129 & $\mathrm{O}$ & $\mathrm{O}$ & 0 \\
\hline 11 & KABUPATENPULANG PSAU & 16 & 69 & 61 & 130 & 69 & 61 & 130 & 23 & 8 & 31 \\
\hline 12 & KABUPATENMURUNG RAYA & 11 & 149 & 69 & 218 & 96 & 50 & 146 & 34 & 12 & 46 \\
\hline 13 & KABUPATENBARTOTIMRR & 30 & 293 & 203 & 496 & 270 & 174 & 444 & 45 & 23 & 68 \\
\hline 14 & KABUPATENPALANGKARAYA & 106 & 1202 & 661 & 1863 & 612 & 538 & 1150 & 407 & 329 & 736 \\
\hline & JUMLAH & 446 & 4594 & 3176 & 7770 & 3359 & 2405 & 5764 & 1385 & 1201 & 2586 \\
\hline
\end{tabular}

3. Data jumlah siswa

Tabel 4. Jumlah siswa SMK Kota Bandung dan Cimahi

\begin{tabular}{|c|l|c|c|c|c|c|}
\hline No. & \multicolumn{1}{|c|}{ KABUPATEN/KOTA } & Tingkat 1 & Tingkat 2 & Tingkat 3 & Tingkat 4 & Total \\
\hline 1 & KOTABANDUNG & 8451 & 10666 & 9466 & 241 & 29090 \\
\hline 2 & KOTACIMAHI & 4505 & 4124 & 3220 & 485 & 12364 \\
\hline & Jumlah & 12956 & 14790 & 12686 & 726 & 41454 \\
\hline
\end{tabular}


Tabel 5. Jumlah siswa SMK Babel

\begin{tabular}{|c|l|c|c|c|c|}
\hline \multirow{2}{*}{ No. } & \multirow{2}{*}{ KOTA / KABUPATEN } & \multicolumn{4}{|c|}{ JUMLAH SISWA SMK } \\
\cline { 3 - 6 } & & Tingkat I & Tingkat II & Tingkat III & Total \\
\hline 1 & KOTA PANGKAL PINANG & 1646 & 1434 & 1267 & 4347 \\
\hline 2 & KABUPATEN BANGKA & 1129 & 976 & 855 & 2960 \\
\hline 3 & KABUPATEN BANGKA BARAT & 689 & 487 & 377 & 1553 \\
\hline 4 & KABUPATEN BANGKA TENGAH & 569 & 449 & 277 & 1295 \\
\hline 5 & KABUPATEN BANGKA SELATAN & 378 & 294 & 200 & 872 \\
\hline 6 & KABUPATEN BEUTUNG & 922 & 849 & 704 & 2475 \\
\hline 7 & KABUPATEN BEUTUNGTIMUR & 361 & 304 & 315 & 980 \\
\hline & JUMLAH & 5694 & 4793 & 3995 & 14482 \\
\hline & & & & & \\
\hline
\end{tabular}

Tabel 6. Jumlah siswa SMK Kalteng

\begin{tabular}{|c|l|c|c|c|c|}
\hline \multirow{2}{*}{ No. } & \multirow{2}{*}{ Nama SMK } & \multicolumn{4}{c|}{ Jumlah Siswa SMK } \\
\cline { 3 - 6 } & & Tingkat 1 & Tingkat 2 & Tingkat 3 & Total \\
\hline 1 & KABUPATEN KOTAWARINGIN BARAT & 543 & 683 & 590 & 1816 \\
\hline 2 & KABUPATEN KOTAWARINGIN TIMUR & 1170 & 862 & 735 & 2767 \\
\hline 3 & KABUPATEN KAPUAS & 537 & 473 & 361 & 1371 \\
\hline 4 & KABUPATEN BARITOSELATAN & 220 & 161 & 94 & 475 \\
\hline 5 & KABUPATEN BARITOUTARA & 440 & 377 & 383 & 1200 \\
\hline 6 & KABUPATEN KATINGAN & 242 & 193 & 216 & 651 \\
\hline 7 & KABUPATEN SERUYAN & 172 & 215 & 193 & 580 \\
\hline 8 & KABUPATEN SUKAMARA & 139 & 188 & 74 & 401 \\
\hline 9 & KABUPATEN LAMANDAU & 200 & 179 & 80 & 459 \\
\hline 10 & KABUPATEN GUNUNGMAS & 136 & 95 & 90 & 321 \\
\hline 11 & KABUPATEN PULANGPISAU & 117 & 96 & 13 & 226 \\
\hline 12 & KABUPATEN MURUNG RAYA & 194 & 112 & 96 & 402 \\
\hline 13 & KABUPATEN BARITOTIMUR & 109 & 95 & 76 & 280 \\
\hline 14 & KABUPATEN PALANGKARAYA & 1125 & 1110 & 826 & 3061 \\
\hline & & 5344 & 4839 & 3827 & 14010 \\
\hline
\end{tabular}

Berdasarkan data-data yang diperoleh secara umum ternyata SMK di Jawa Barat masih didominasi oleh SMK Swasta sebanyak 93\% sedangkan negeri hanya 7\%. Fakta dan Fenomena ini terjadi karena keterbatasan anggaran dari pemerintah untuk membangun sekolah negeri. Sementara disisi lain dana pendamping dari Pemerintah provinsi maupun kabupaten juga terbatas. Ditambah lagi Kebijakan direktorat untuk pendirian Unit Sekolah Baru (USB) satu kabupaten rata rata 1 buah menambah keterlambatan tercapainya target pendirian SMK negeri. Lepas dari persoalan tersebut yang harus dilakukan saat ini di Jawa Barat adalah meningkatkan dan mendorong terus kualitas dan 'academic atmosphere' SMKSMK swasta yang ada. Mereka harus dibantu secara sistematis, terencana dan terprogram sehingga kultur kinerja nya akan mendekati 'mind set' SMK negeri. Program peningkatan kompetensi guru, perbaikan dan penambahan laboratorium, pelatihan manajemen dan perbaikan kesejahteraan SDM sudah saat nya SMK swasta mendapat ruang yang sama dengan SMK negeri. Asumsi SMK swasta kelas 2, sekolah asal jalan, hanya terima ijazah serta banyak manupalasi data harus mulai dikikis habis. Berdayakan dan harus dibantu mereka tentunya dengan beberapa kondisi yang ditetapkan pemerintah, ada pengawasan ketat guru, kendali proses belajar serta monitoring seluruh proses akademik yang terjadi. Data selengkapnya dapat diperiksa pada gambargamber berikut : 


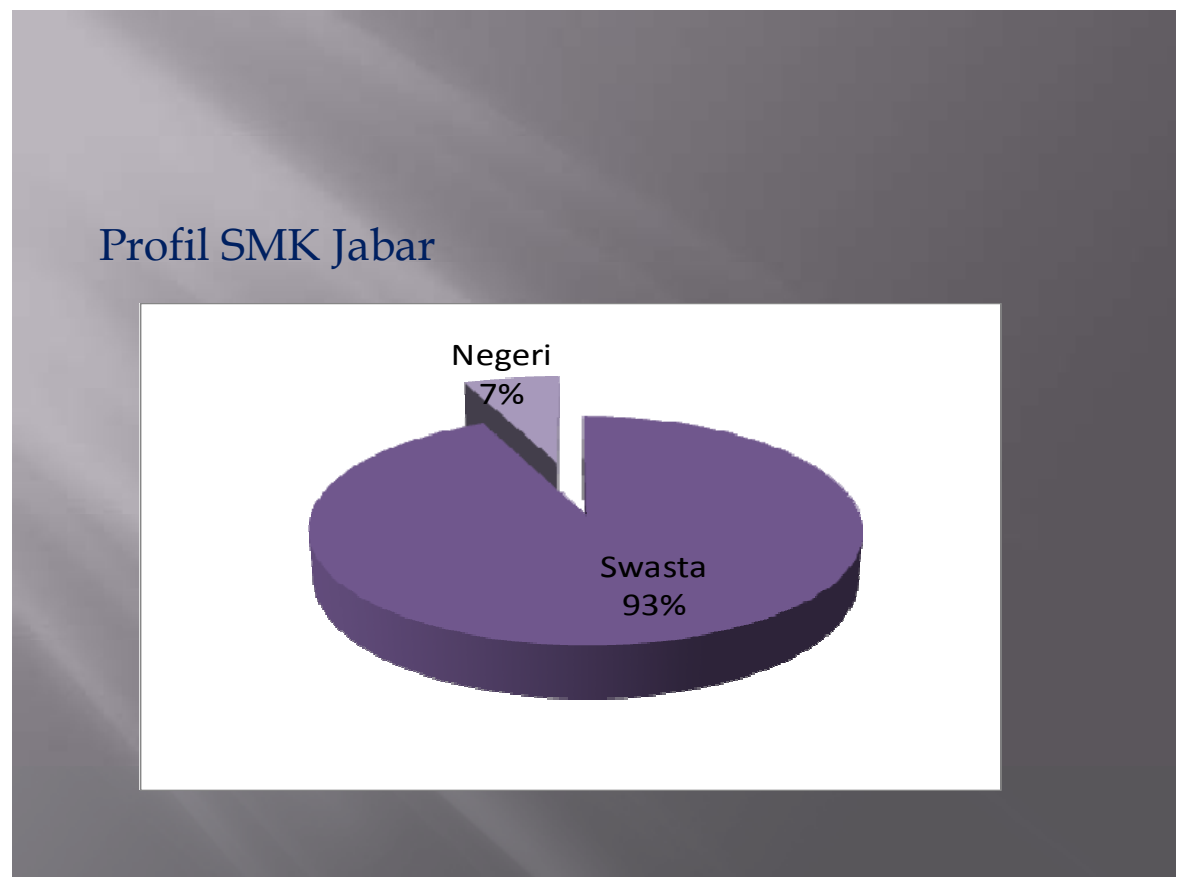

Gb. 1 Diagram Profil SMK Jawa Barat

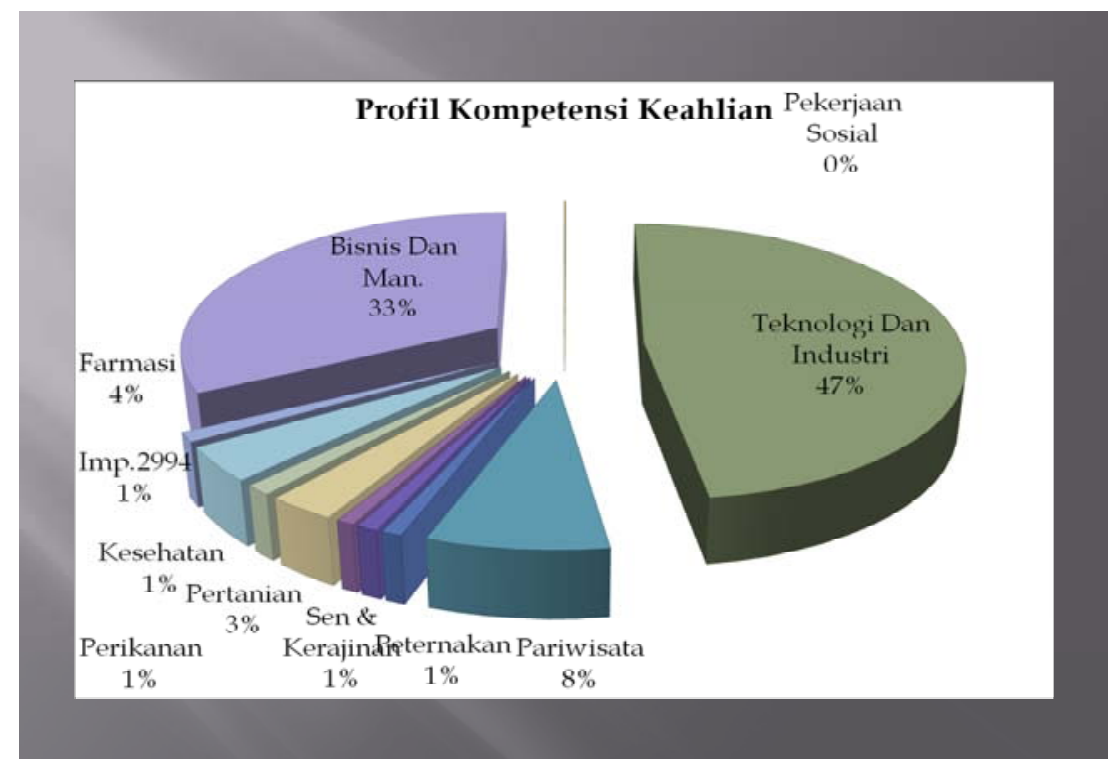

Gb. 2 Diagram Profil Komptetensi di Jawa Barat

Dari pemetaan kompetensi keahlian SMK Negeri/swasta di Jawa Barat masih di dominasi oleh bidang Teknologi dan Indsutri $47 \%$ salah satu icon terbesar nya adalah bidang otomotif. Kemudian bidang teknik elektro, otomasi dan infprmatika. Kompetensi kehlian peringkat kedua jatuh pada bidang Bisnis dan Manajemen yang berada pada besaran 33 \%. Sedangkan kompetensi lainnya jauh di bawah seperti 
pariwisata 8\%, farmasi $4 \%$ dan menyusul pertanian $3 \%$ sedangkan kompetensi lain rata-rata $1 \%$. Dari data ini terlihat Jawa Barat masih merupakan kawasan indsutri yang cukup potensial.

Tentu saja harus merupakan bahan kajian penting berbagai fihak terkait. Baik itu dikti, direktorat SMK, LPTK, asosiasi profesi, pemerintah propinsi maupun pemerintah kabupaten/kota karena secara sistematis akan memberikan dampak multiplier yang cukup besar. Salah satu nya adalah kualitas lulusan yang betul-betul dapat bersaing secara kompetitif. SMK beda dengan SMA didalamnya terintegrasi berbagai fihak bukan hanya lingkungan sekolah denga segala isinya tapi juga ada industry terkait, lembaga-lembaga sertifikasi, dan fihak-fihak lain yang terkait dengan pemasaran produk siswa.

Sistem penJaminan mutu (quality assurance) yang dikembangkan harus mulai dari hulu sampai ke hilir. Mulai dari guru ini pasti terkait dengan LPTK JPTK/FPTK yang ada peningkatan kualitas mulai dari lembaga ini dengan menyiapkan infra struktur yang lebih baik dibandingkan dengan SMK yang terjadi selama ini justeru sebaliknya.

Sedangkan data-data lain dapat diperiksa pada diagram berikut

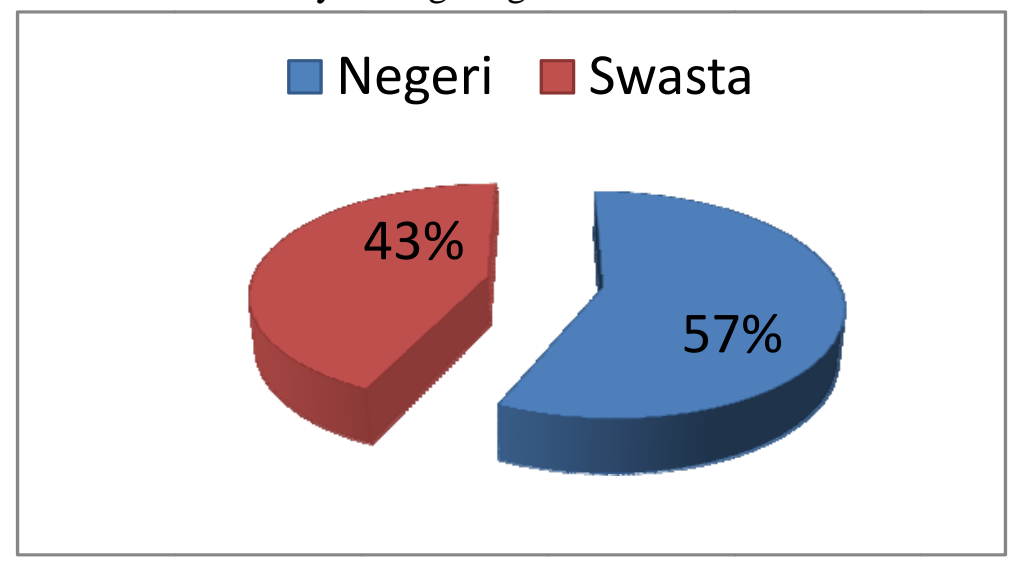

Gb. 3 Diagram Profil Status SMK di Kalimantan Tengah

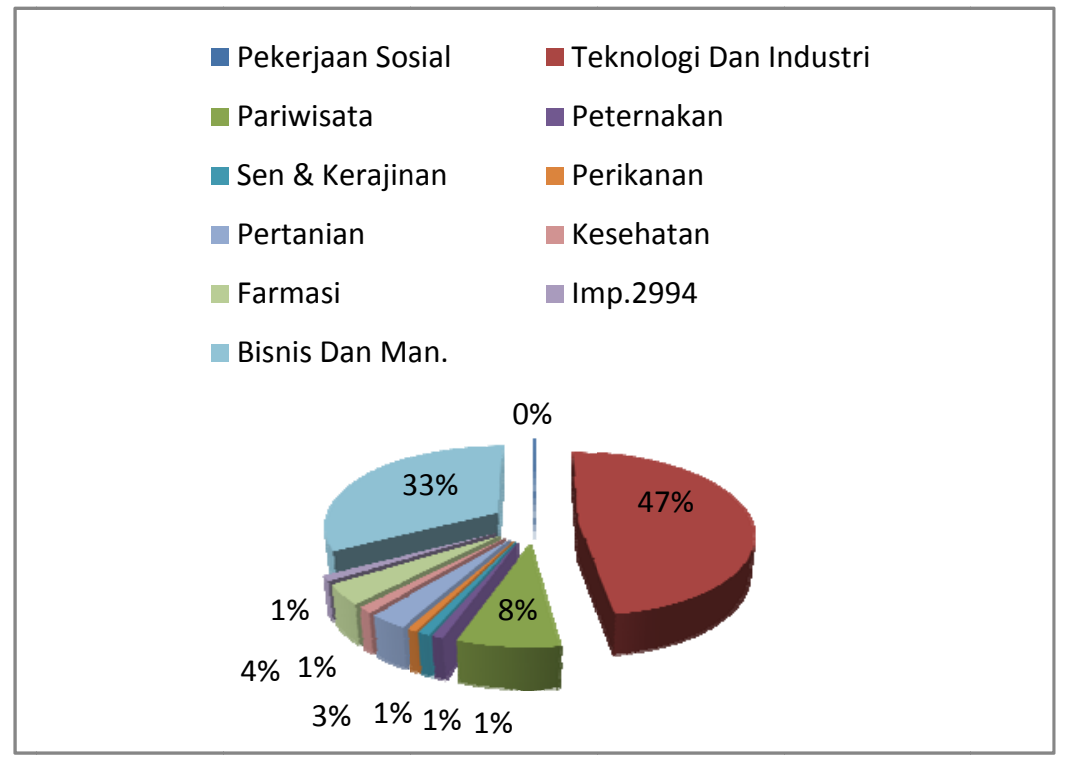

Gb. 4 Diagram Program Keahlian SMK di Kalimantan Tengah 


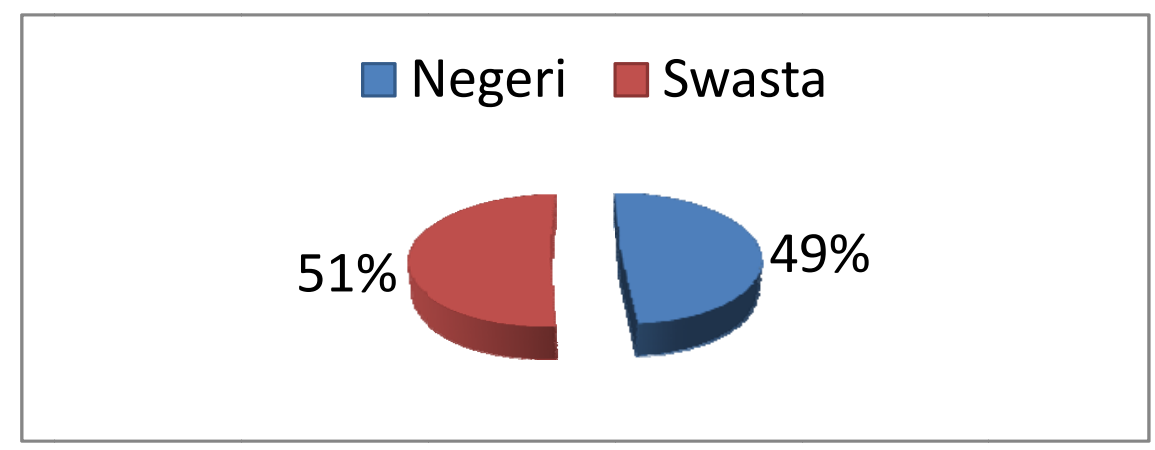

Gb 5. Diagram profil SMK di Bangka Belitung

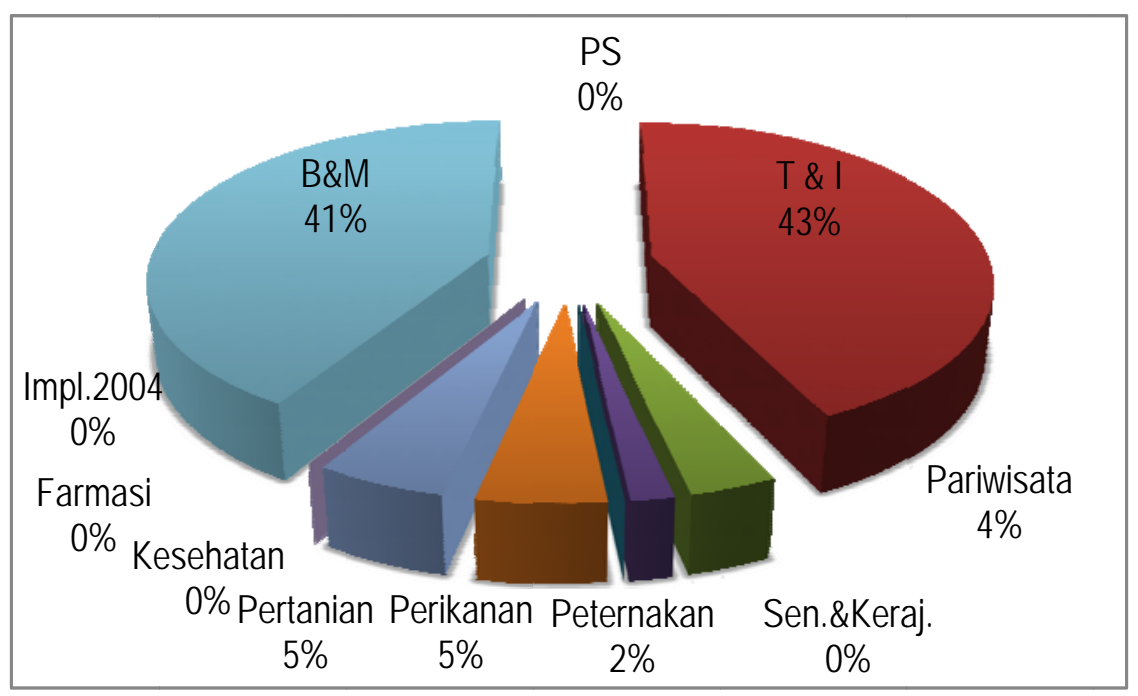

Gb. 6 Diagram profil program keahlian SMK di Bangka Belitung

Berdasarkan data jumlah SMK yang diperoleh dari Dinas Pendidikan Propinsi dan setelah diverifikasi dengan data PSMK 2009, terdapat perbedaan menyangkut hal-hal berikut :

1. Terdapat deferensiasi signifikan program kompetensi

2. Terdapat SMK yang baru sehingga belum tercantum dalam data versi PSMK (diberi warna merah).

3. Terdapat SMK yang sudah tercantum dalam Buku 1 PSMK namun belum lengkap datanya. Kelengkapan data mengacu pada data dari Dinas Pendidikan Propinsi (diberi warna biru)

4. Terdapat SMK yang tercantum dalam buku 1 PSMK, namun tidak terdapat dalam data Dinas Pendidikan Propinsi. (data ini dihilangkan)

Mengacu pada data penerimaan siswa baru dengan jumlah lulusan tahun 2009, terdapat perbedaan yang sangat signifikan, yakni jumlah siswa yang diterima jauh lebih banyak dari pada jumlah siswa yang lulus dengan selisih lebih dari 100\%. Hal ini perlu dicermati dan harus menjadi bahan pertimbangan pihak terkait dalam merencanakan pengembangan pendidikan SMK. Peningkatan ini di satu sisi merupakan indicator keberhasilan meningkatkan animo masyarakat pada pendidikan SMK, namun di sisi lain merupakan boomerang bagi pemerintah apabila tidak mampu menyelenggarakan pendidikan yang bermutu 
dan menyediakan lapangan kerja yang sesuai, sehingga dikhawatirkan nanti masyarakat akan antipati terhadap pendidikan SMK.

Fakta tersebut di atas diperkuat oleh data jumlah siswa tiap angkatan, dimana jumlah siswa setiap tahunnya semakin meningkat dengan peningkatan yang cukup signifikan. Peningkatan jumlah siswa mengharuskan pihak sekolah membuat strategi yang tepat agar proses pembelajaran dapat berlangsung dengan lancar, efektif, dan efisien.

\section{KESIMPULAN}

Beberapa kesimpulan yang dapat ditarik dari hasil penelitian ini adalah sebagai berikut :

1. Secara agregat konstalasi dinamika pendidikan SMK menuju kearah yang benar seuai dengan skenario direktorat SMK:SMA 70:30

2. Program Kompetensi prioritas di tiap propinsi memiliki karakteristik tersendiri

3. Terjadi peningkatan (eskalasi) jumlah siswa baru yang sangat signifikan pada pendidikan SMK.

4. Terdapat kesenjangan yang sangat besar antara jumlah lulusan dengan jumlah siswa baru yang diterima pada pendidikan SMK.

5. Program keahlian Mekanik Otomotif, menjadi program keahlian yang paling banyak jumlah rombongan belajarnya.

6. Terdapat kekurangan guru yang signifikan berkaitan dengan peningkatan jumah siswa SMK.

\section{DAFTAR PUSTAKA}

Arikunto S. (1988). Perencanaan dan pengembangan kurikulum pendidikan teknologi dan kejuruan. Jakarta: P2LPTK.

Evans, Rupert N. (1971). Foundation of vocational education. Columbus: Charles E. Merril Publishing Co.

Mulyasa E. (2002). Manajemen Berbasis Sekolah, Konsep, Strategi, dan Implementasi. Bandung: Remaja Rosdakarya.

Soewono. (2002). Pendidikan Berbasis Kompetensi.

Sukamto. (1988). Perencanaan dan pengembangan kurikulum pendidikan teknologi dan kejuruan. Jakarta: P2LPTK.

Suyitno. (2004). Isu Strategik dalam Pengelolaan Pendidikan Tinggi. Jurnal Ilmiah dalam Konvensi Nasional Aptekindo II dan Temu Karya XIII FT/FPTK/JPTK Universitas/IKIP se Indonesia. Jakarta.

Thompson, John F. (1973). Foundation of vocational education. New Jersey: Prentice-Hall, Inc.

Thorogood, Ray. (1982). Current themes in vocational education and training polices: Part I. Industrial and Commercial Training.

Wenrich, Ralph C. dan J. William Wenrich. (1974). Leadership in administration of vocational and technical education. Columbus: Charles E. Merril Publishing Co.

*) Dosen Jurusan Pendidikan Tekbik Elektro FPTK UPI

**) Dosen Jurusan Pendidikan Teknik Mesin FPTK UPI 